\title{
Three-Dimensional Analysis of Buried Steel Pipes under Moving Loads
}

\section{Bahram Navayi Neya1, Mehdi Alijani Ardeshir'1, Ali Aghajani Delavar², Mohammad Zaman Roshan Bakhsh'}

${ }^{1}$ Faculty of Civil Engineering, Babol Noshirvani University of Technology, Babol, Iran

${ }^{2}$ Mazandaran Gas Company, Sari, Iran

Email: Navayi@nit.ac.ir

How to cite this paper: Neya, B.N., Ardeshir, M.A., Delavar, A.A. and Bakhsh, M.Z.R. (2017) Three-Dimensional Analysis of Buried Steel Pipes under Moving Loads. Open Journal of Geology, 7, 1-11. http://dx.doi.org/10.4236/ojg.2017.71001

Received: September 7, 2016

Accepted: January 9, 2017

Published: January 12, 2017

Copyright (C) 2017 by authors and Scientific Research Publishing Inc. This work is licensed under the Creative Commons Attribution International License (CC BY 4.0).

http://creativecommons.org/licenses/by/4.0/ (c) (i) Open Access

\begin{abstract}
The three-dimensional response of buried steel pipes under vehicle loads is investigated using the finite element analysis. The analysis is conducted using the finite element program ABAQUS. The effects of the vehicle parameters, pipeline parameters and soil parameters on the response of the buried pipeline were discussed. The results indicate that the maximum principal stresses in a buried pipe under vehicle loads are significant for burial depths of less than 1 $\mathrm{m}$. The maximum principal stresses of the buried pipeline decrease as the burial depth, vehicle velocity and surrounding soil's elasticity modulus increase. For small burial depths, the stresses in buried pipes caused by vehicle motion in the direction normal to the pipe axis are more critical. However, the effects of motion direction are insignificant when the burial depth and the surrounding soil's elasticity modulus increase. As the diameter of a buried pipe decreases, the maximum principal stresses increase.
\end{abstract}

\section{Keywords}

Buried Steel Pipeline, Vehicles Load, Motion Direction, Numerical Simulation, Stress

\section{Introduction}

Gas pipeline system as one of the vital arteries due to passing through different areas is exposed to many local factors such as roads, railways, bridges, embankments, mechanical equipment, etc. In this regard, live loads caused by the movement of vehicles may considerably affect the performance of buried pipe [1]. According to the investigation, local destructive effects appear on many sections of the pipeline under the surface load [2]. On the other hand, inspection and maintenance of the pipelines are not done under the loading areas [3]. 
Therefore, analysis of the buried pipelines under wheel load is necessary for its safety design. The studies on trench cavities generally suggest that the pressure caused by a concentrated surface load, e.g. that of a vehicle wheel weight, is very similar to the pressure distribution obtained from Boussinesq solution of a concentrated load on a semi-infinite medium [4]. However, this may be illogical for pipes under shallow burial. In these cases, mechanical behavior of the pipe under wheel load would be a three-dimensional phenomenon [5]. The simplest analysis on buried pipelines were conducted by Newmark and Hall [6], in which no interactions were considered between soil and pipe. In other words, pipeline deformations were considered dependent on the ground deformations. Wang et al. [7] used beam-spring model to study axial deformations in buried pipelines, in which soil-pipe interactions were taken into consideration. Selberg [8] investigated an elastic medium under the effect of instant pressure on the inside of the cavity surface. Jordan [9] studied the same problem with linear dynamic pressure acting upon the part of the cavity wall. Parnes [10] studied the effects of applying a linear torsional stress, moving in a circular motion along the cylindrical cavity axis in an infinite elastic medium. Sneddon [11] investigated the 2D case of Parnes problem.

Cheng and Ger [12] were one of the firsts to numerically study and analyze pipes. In their study, they assumed 3D nodes with 3 degrees of freedom (DOF). Wong et al. [13] investigated 3D, dynamic analysis of buried pipelines in plane stress conditions, assuming soil-pipe interactions exist. The proposed model can assess local buckling and axial displacement. Winkler's theory was used to model soil-pipe interactions. Liu and Yang [14] used ABAQUS software package to model buried pipelines under impact force of falling objects. They investigated the effects of relative hardness and burial depth on stress distribution of buried pipes. The results suggest that pipe stress decreases as soil-pipe relative hardness and burial depth decrease. However, pipe stress remains constant in burial depths greater than $3 \mathrm{~m}$. Gong and Sun [15] researched mechanical properties of the pipelines underground surcharge but did not consider the plastic strain. Shuai [2] studied the stress and deformation of buried pipeline under a ground load by using a 3D finite element model of pipeline-foundation system. The results show that surface load induces local bending and ovalization of the pipeline due to non-uniform effects of overlying soil and tamping foundation. Noor [5] studied the three-dimensional finite element analysis of a buried concrete pipe under vehicle loads and showed that the soil-pipeline interaction should be considered for shallow buried pipeline. Zhang [16] investigated the buckling behavior of the buried steel pipeline under reverse fault displacement. Zhang and Liang [17] studied the mechanical behavior analysis of a buried steel pipeline underground overload. However, there are few studies on the effect of vehicle load on buried pipelines. In the present study, a 3D analysis of buried steel pipeline under vehicle load was investigated using numerical simulation. The effects of vehicle load, pipe characteristics and Young's modulus as well as Poisson's ratio of soil on the behavior of buried pipe were discussed. The maximum principal 
stresses in soil and pipe were determined in different cases. The results presented can be used as a reference for the safety evaluation of buried pipelines.

\section{Finite Element Simulation}

Numerical analyses of the buried steel pipeline under vehicle load have been carried out using finite element computer software ABAQUS (2013). The linear material behavior of the steel pipeline and surrounding soil, the interaction between the soil and the pipeline are modeled. Vehicle wheel load was modeled as a moving load with constant velocity. Wheel load was applied to a specific surface in two rows based on wheel pressure. The effect of moving load was modeled in ABAQUS by a DLOAD subroutine. The schematic diagram of a buried pipeline under a wheel load is shown in Figure 1.

As demonstrated in Figure 1(a), the direction of the moving wheel load was considered normal to the pipe axis. Figure 1 (b) shows the moving direction parallel to pipe axis. Solid elements of type C3D20 was used in this study to model soil and pipe mediums. The elements are cube-shaped and isoparametric, and are of second degree with 20 nodes. Each node has 3 DOF and uses 27 integration points. Figure 2 shows the finite element models of buried pipeline and surrounding soil. Sensitivity analysis was performed on soil and pipe meshes to

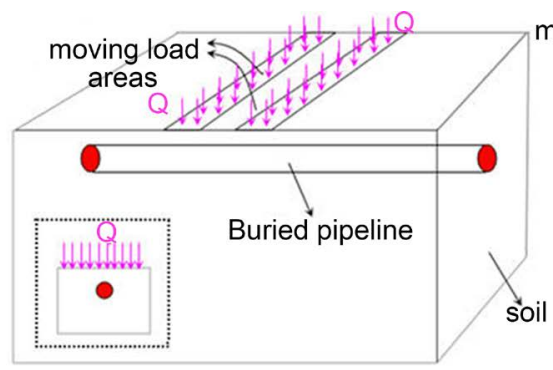

(a)

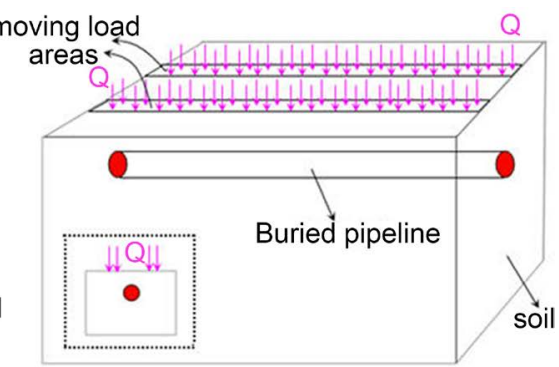

(b)

Figure 1. Schematic diagram of the buried pipeline under moving load. (a) Perpendicular motion; (b) Parallel motion.

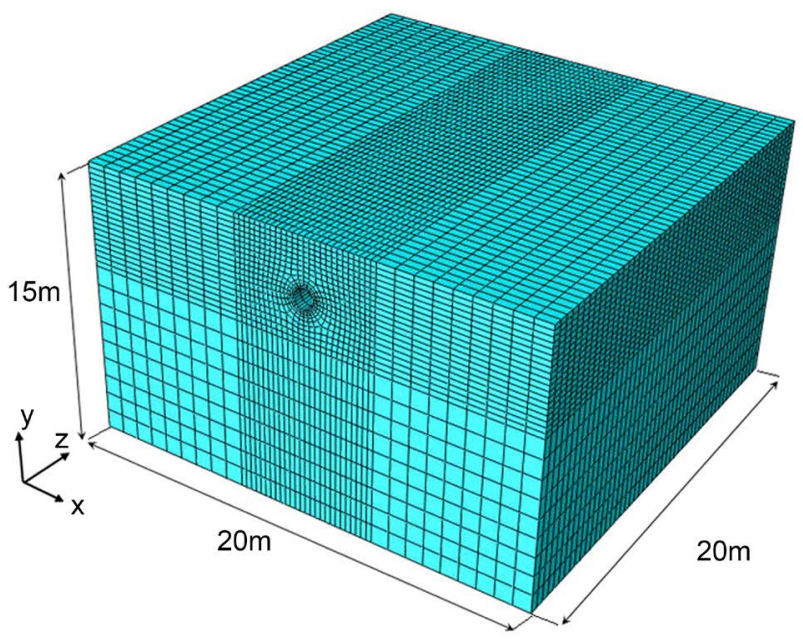

Figure 2. Finite element models. 
derive an optimized meshing size. The results were then used in our final simulations. The size of the whole model is $20 \mathrm{~m} \times 15 \mathrm{~m} \times 20 \mathrm{~m}$. Gravity loading and internal pressure were applied first and subsequently wheel load was imposed. Nodes on the bottom boundary plane of the model are remain fixed in the y direction. Nodes on lateral planes of the cubic model remain fixed in the direction normal to their plane.

Material parameters are chosen as the typical values for steel and soil material. Due to diverse geotechnical properties of soil, 5 types of soil were considered according to Table 1.

Numerical results are obtained for the X45 steel pipeline. The Young's modulus of the steel is $210 \mathrm{GPa}$, Poisson's ratio is 0.3 , and the density is $7850 \mathrm{~kg} / \mathrm{m}^{3}$. Geometrical properties of the pipeline provided in Table 2.

To model the soil-pipe interactions using finite element method (FEM), the interface between the pipeline and the surrounding soil was simulated using a contact algorithm of surface-to-surface type. For tangential contacts, penalty coefficients of 0.3 were used for the two surfaces as the friction coefficient. Normal surface contacts were considered as hard contacts.

\section{Effects of Vehicle Parameters}

\subsection{Motion Direction Effect}

The effect of vehicle moving direction relative to the pipeline was investigated on the responses of the soil-pipe medium. To this end, the vehicle moving direction was considered both parallel and normal to the pipe axis in two different scenarios. Maximum principal stresses in a steel pipe of 4-inch diameter for the two aforementioned cases are demonstrated in Figure 3, where the vehicle moves at $30 \mathrm{~km} / \mathrm{h}$.

As can be seen in Figure 3, for small burial depths, maximum principal stresses in the steel pipe due to the moving vehicle are more critical in the direction parallel to the pipe axis. However, as burial depth and Young's modulus of the soil increase, the results of the two directions converge to the same values. Maximum principal stresses in two steel pipes of 20- and 44-inch diameters under vehicle loads moving in two different directions are presented in Figure 4 and Figure 5, respectively.

Table 1. soil properties used in modeling.

\begin{tabular}{cccccc}
\hline & Type 1 & Type 2 & Type 3 & Type 4 & Type 5 \\
\hline Modulus of elsticity (Mpa) & 5 & 15 & 50 & 75 & 100 \\
Density $\left(\mathrm{kg} / \mathrm{m}^{3}\right)$ & 1820 & 1950 & 1950 & 1950 & 2050 \\
Poisson's ratio & 0.4 & 0.3 & 0.25 & 0.25 & 0.2 \\
\hline
\end{tabular}

Table 2. geometrical properties of the steel pipe.

\begin{tabular}{cccccccc}
\hline Diameter $(\mathrm{mm})$ & 114 & 273 & 406 & 508 & 601 & 762 & 1117 \\
\hline Thickness $(\mathrm{mm})$ & 4.3 & 5.5 & 7.1 & 9.4 & 11.3 & 14.5 & 19 \\
\hline
\end{tabular}




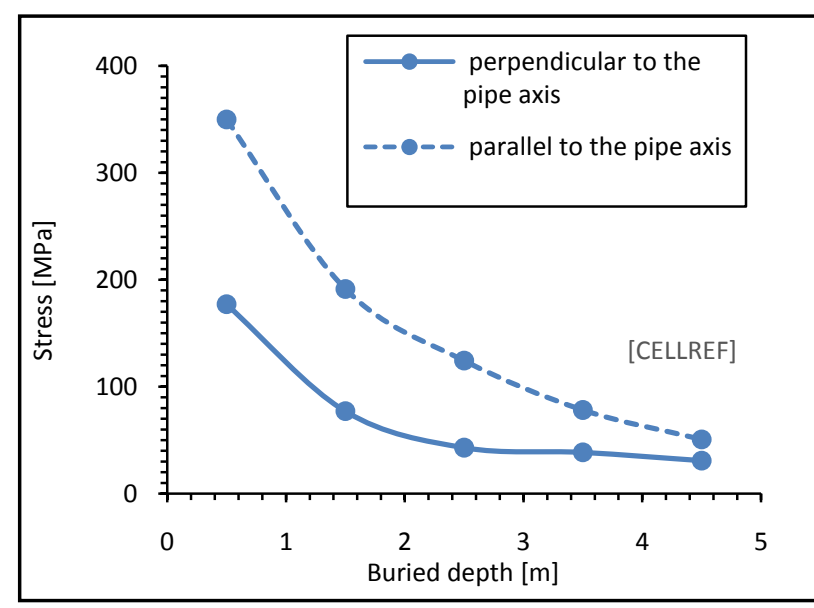

(a)

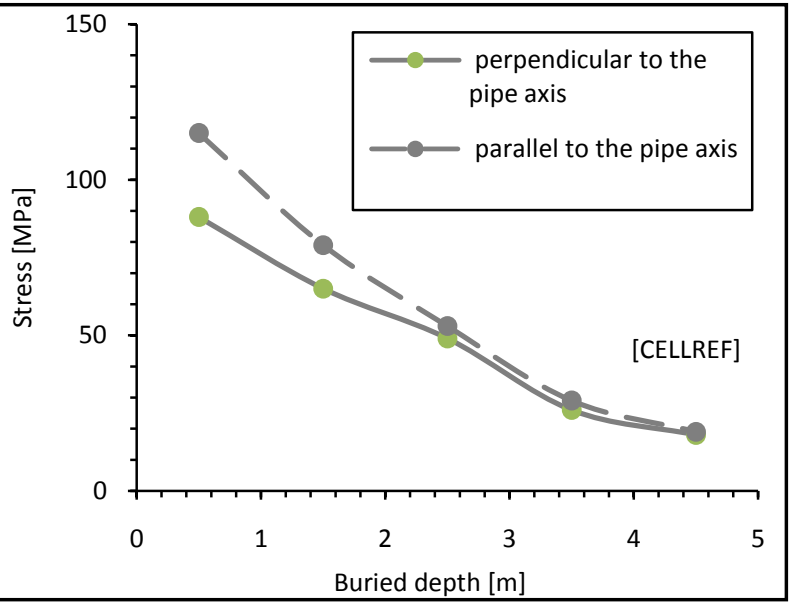

(b)

Figure 3. Maximum principal stresses in a 4-inch diameter steel pipe for different vehicle moving directions.

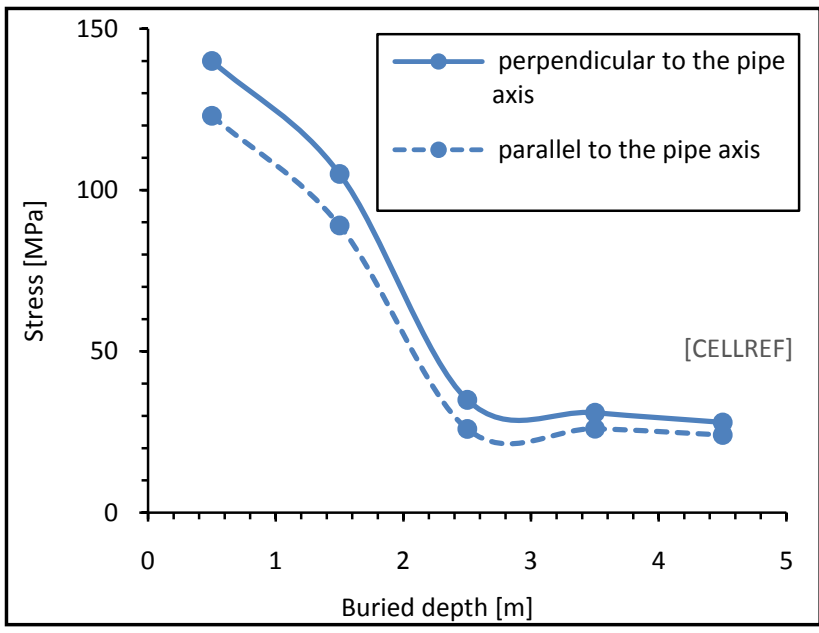

(a)

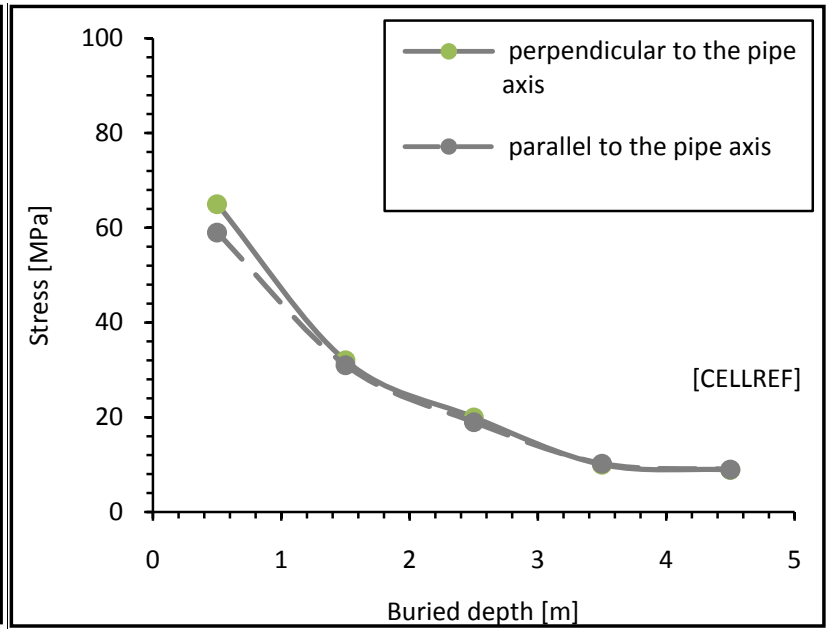

(b)

Figure 4. Maximum principal stresses in a 20-inch diameter steel pipe for different vehicle moving directions.

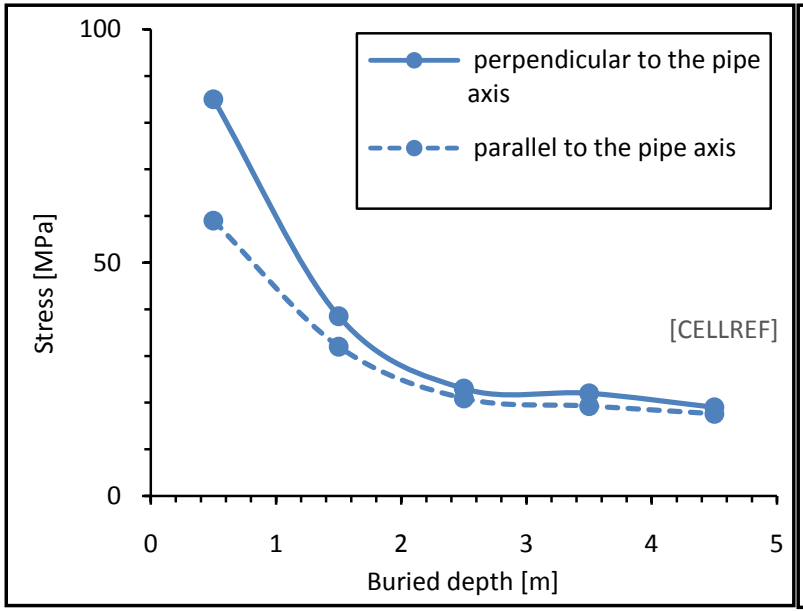

(a)

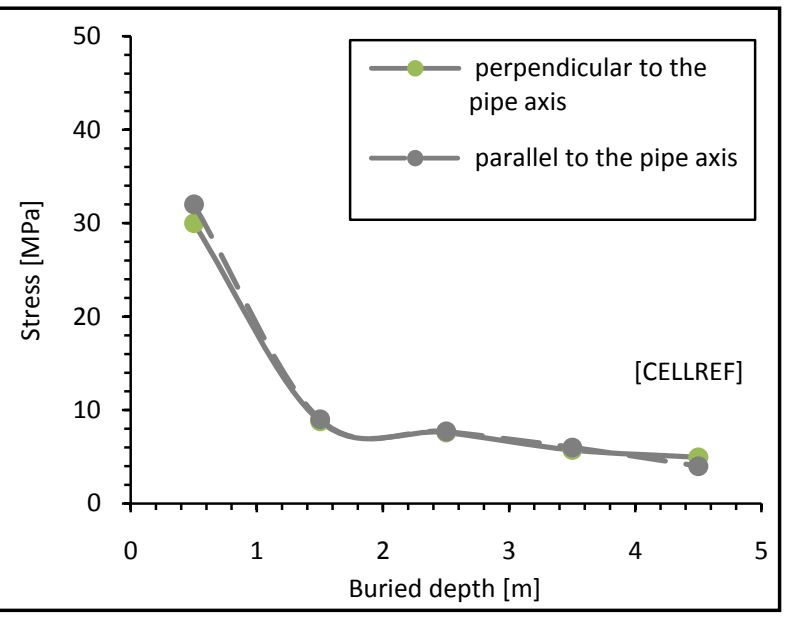

(b)

Figure 5. Maximum principal stresses in a 44-inch diameter steel pipe for different vehicle moving directions. 
As demonstrated in Figure 4 and Figure 5, an increase in pipe diameter results in faster convergence of steel pipe stress diagrams for both vehicles moving directions, such that the corresponding diagrams for the soil of type 3 and 44-inch pipe diameter nearly overlap.

\subsection{Vehicle Velocity Effect}

In this section, the effect of vehicle velocity on the responses of soil medium and pipe was investigated. Therefore, vehicle velocities of $30 \mathrm{~km} / \mathrm{h}, 45 \mathrm{~km} / \mathrm{h}$ and 60 $\mathrm{km} / \mathrm{h}$ were assumed in this study. Maximum principal stresses in two steel pipes of 20- and 44-inch diameters under vehicle loads of different velocities are shown in Figure 6 and Figure 7, respectively. As can be seen from these figures, maximum principal stresses in the steel pipe decrease as the vehicle velocity increases. The magnitude of this decrease is inversely proportional to the burial depth and Young's modulus of the soil.

Maximum principal stresses in a 44-inch steel pipe under vehicle loads of

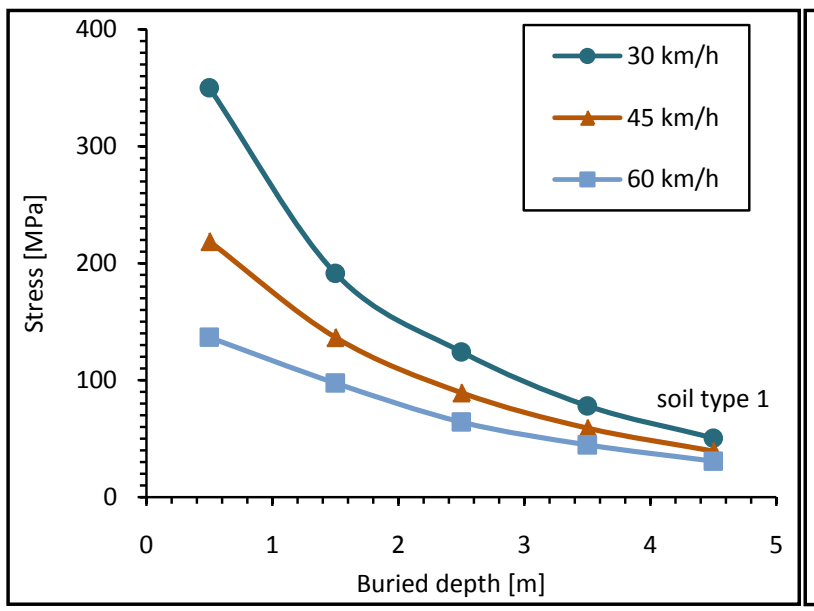

(a)

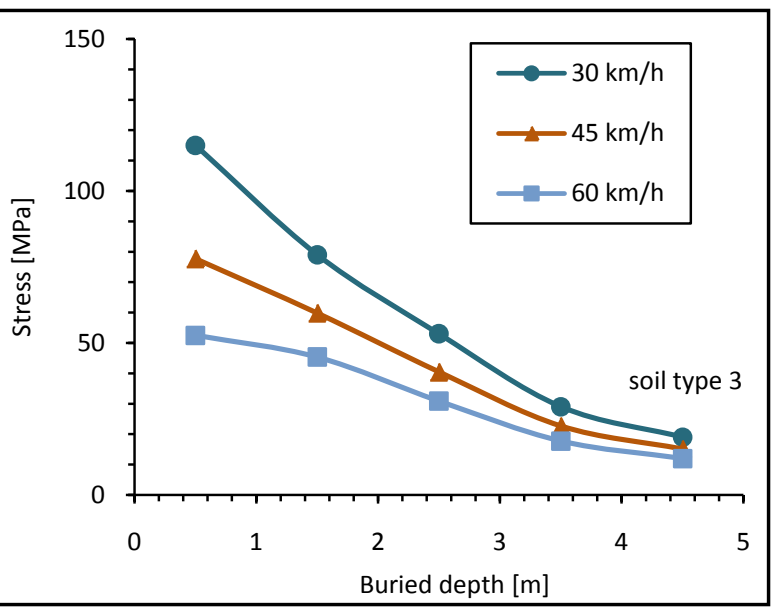

(b)

Figure 6. Maximum principal stresses in a 4-inch diameter steel pipe for different vehicle velocity.

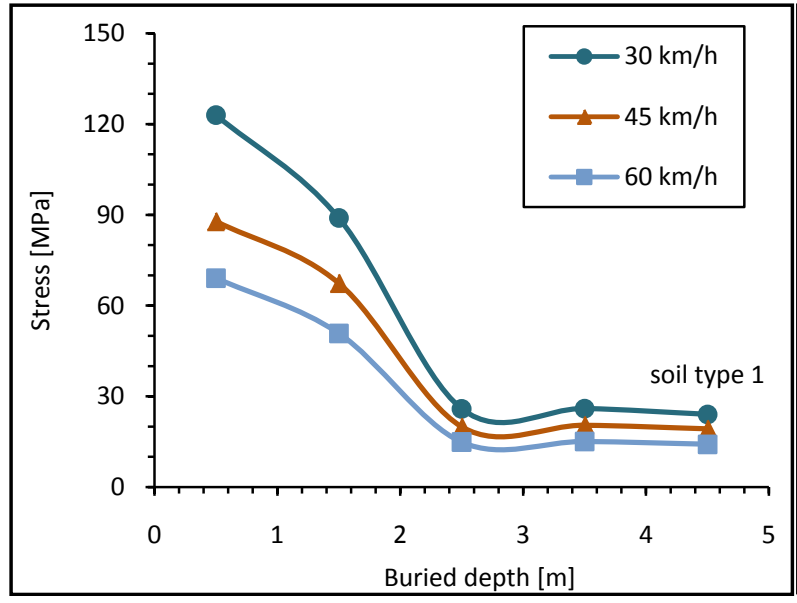

(a)

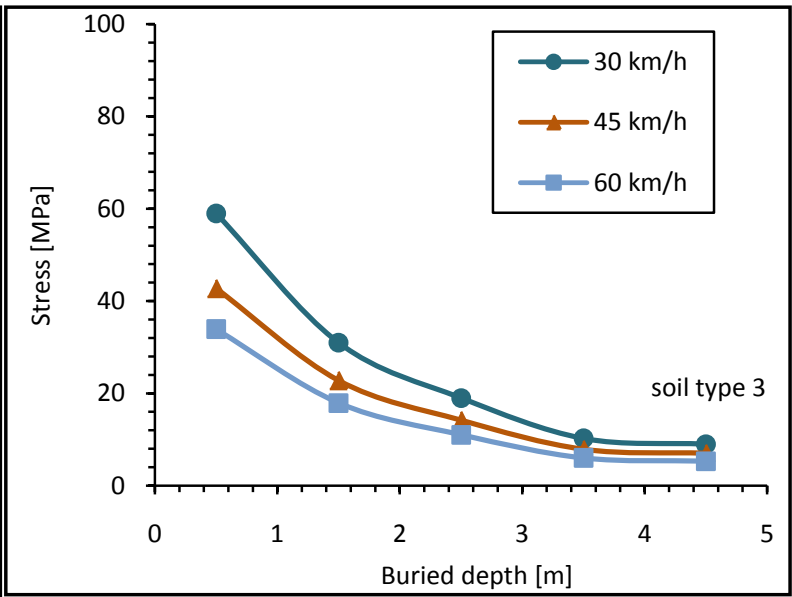

(b)

Figure 7. Maximum principal stresses in a 20-inch diameter steel pipe for different vehicle velocity. 
different velocities are depicted in Figure 6.

As Figure 8 demonstrates, increase in pipe diameter and burial depth results in faster convergence of steel pipe stress diagrams for different vehicle velocities, such that the corresponding diagrams for the soil of type 3 and 44-inch pipe diameter nearly overlap.

\section{Effects of the Pipeline Parameters}

Maximum principal stresses in steel pipes with different diameters are depicted in Figure 9 for a vehicle velocity of $30 \mathrm{~km} / \mathrm{h}$ in the same direction as the pipe axis. The results are shown separately for different types of soil. Figure 9 suggests that maximum principal stresses decrease as pipe diameter increases. The magnitude of this decrease is inversely proportional to burial depth. In addition, as burial depth and Young's modulus of soil increase, stress diagrams converge more quickly.

Generally, the decrease in diameter-to-thickness ratio results in lower maximum principal stresses, such that in diameter-to-thickness ratios of smaller than 30 , the maximum principal stress in the steel pipe is negligible.

\section{Effects of the Surrounding Soil Parameters}

Maximum principal stresses in steel pipes buried in different soil types are depicted in Figure 10 for a vehicle velocity of $30 \mathrm{~km} / \mathrm{h}$ in the same direction as the pipe axis.

The additional force caused by vehicle load acts on the buried steel pipeline by surrounding soil. Surrounding soil is the media between the vehicle load and the buried pipeline. Because the deformation of the surrounding soil with a lower elasticity modulus is bigger, the action of the overlying soil on the buried pipeline is greater. Therefore, as Young's modules of the soil increases, maximum principal stresses in the steel pipe decreases, such that for Young's moduli of greater than $20 \mathrm{MPa}$, maximum principal stresses in the steel pipe are negligible.

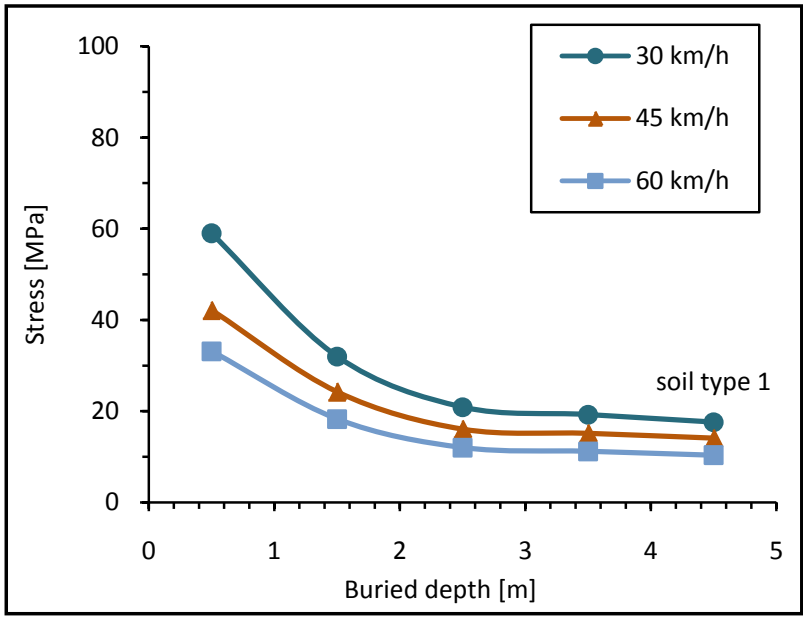

(a)

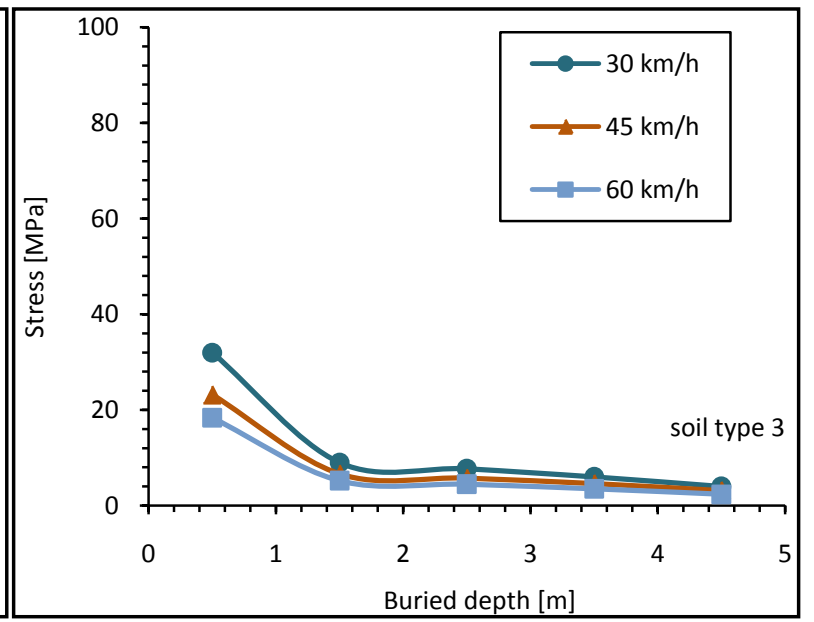

(b)

Figure 8. Maximum principal stresses in a 44-inch diameter steel pipe for different vehicle velocity. 


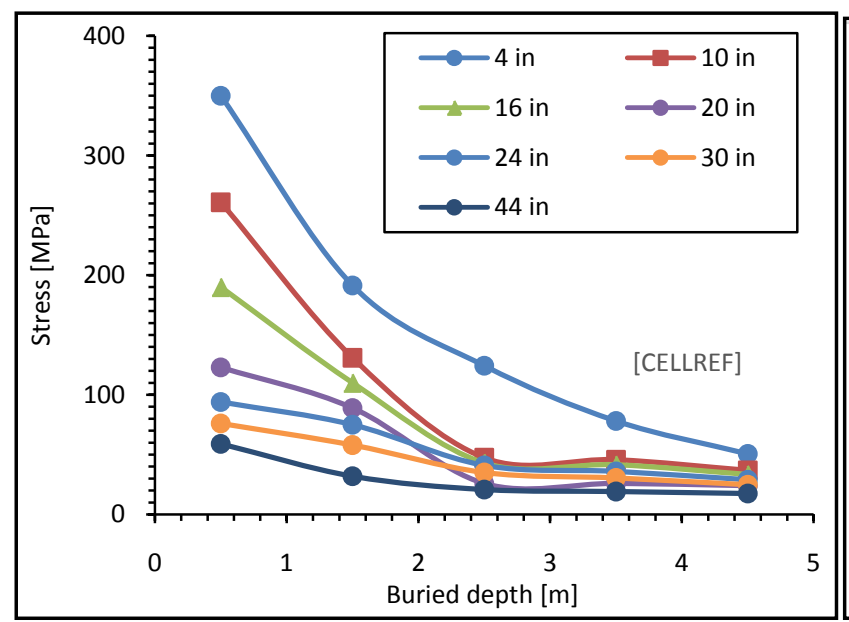

(a)

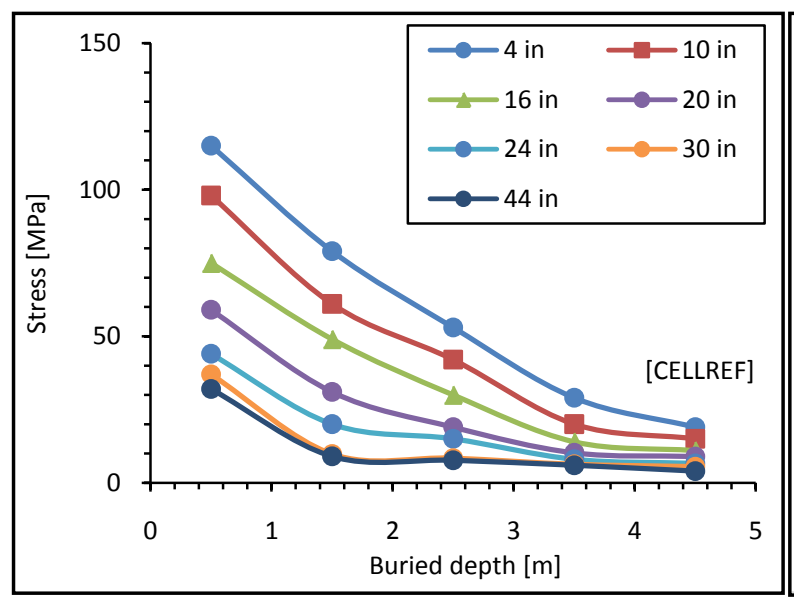

(c)

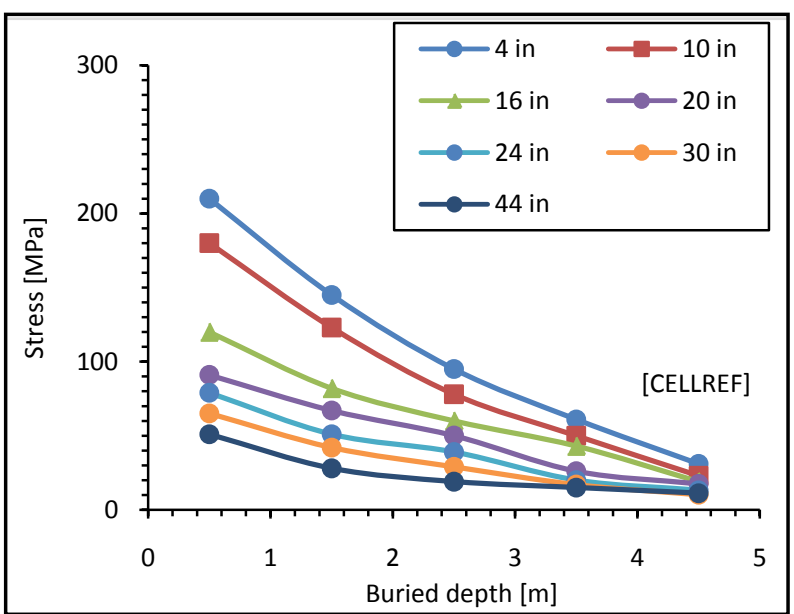

(b)

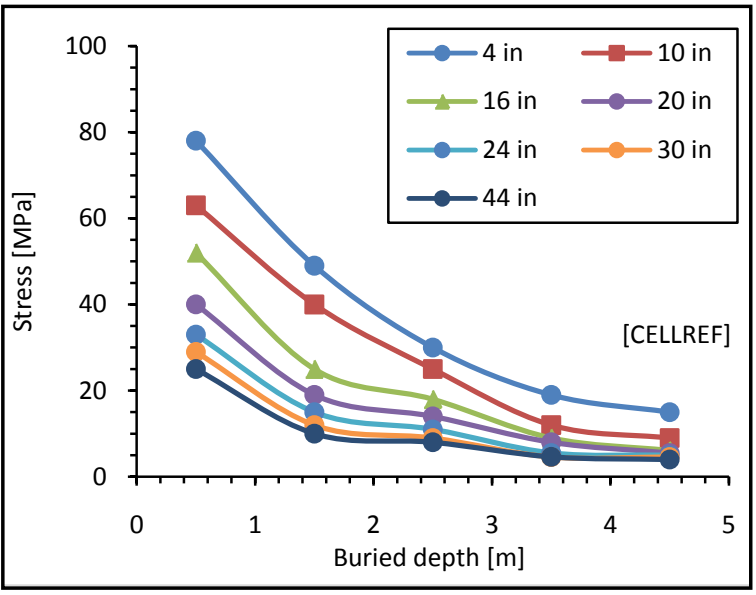

(d)

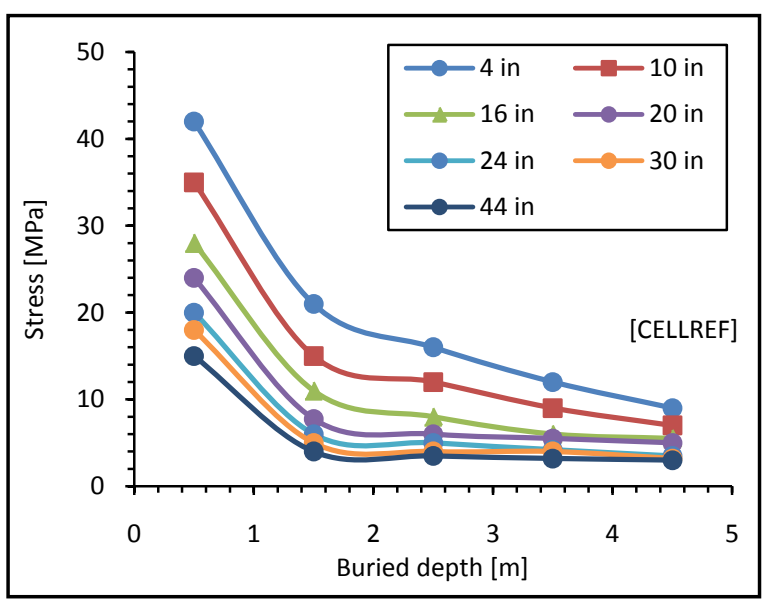

(e)

Figure 9. Maximum principal stresses in the steel pipe with different Diameter.

Moreover, stress diagrams converge more quickly as burial depth and Young's modulus of the soil increases. The decrease in Poisson's ratio results in lower principal stresses. The magnitude of this decrease is inversely proportional to the burial depth. 


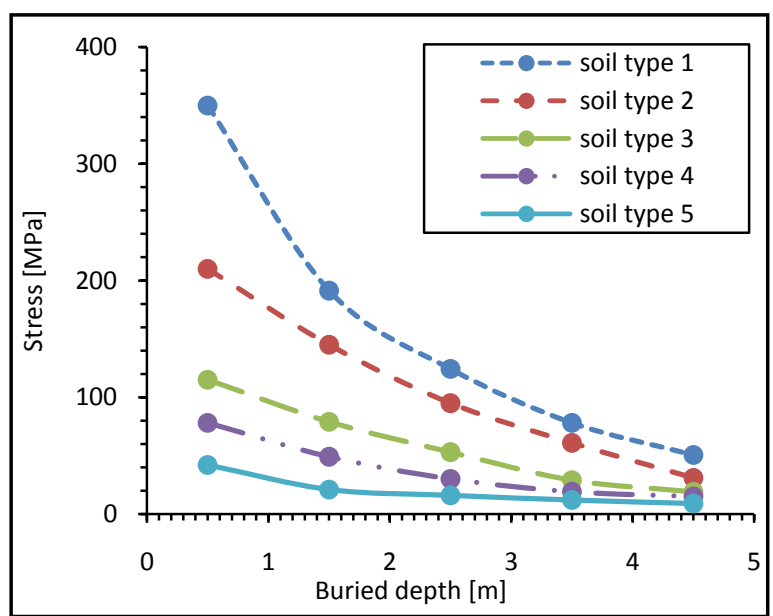

(a)

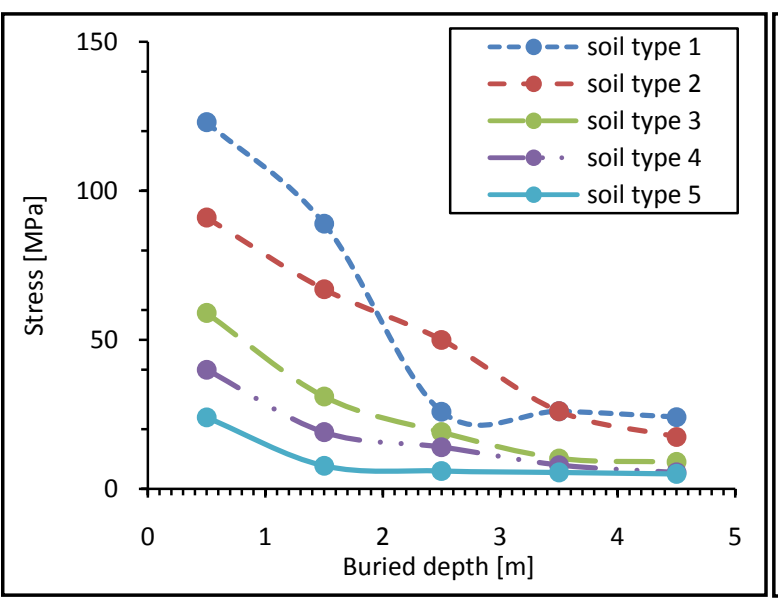

(c)

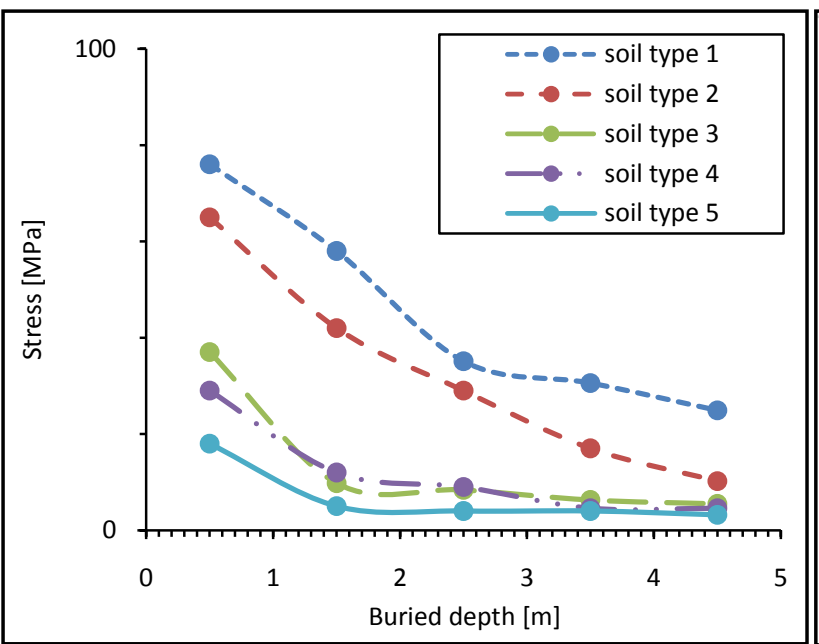

(e)

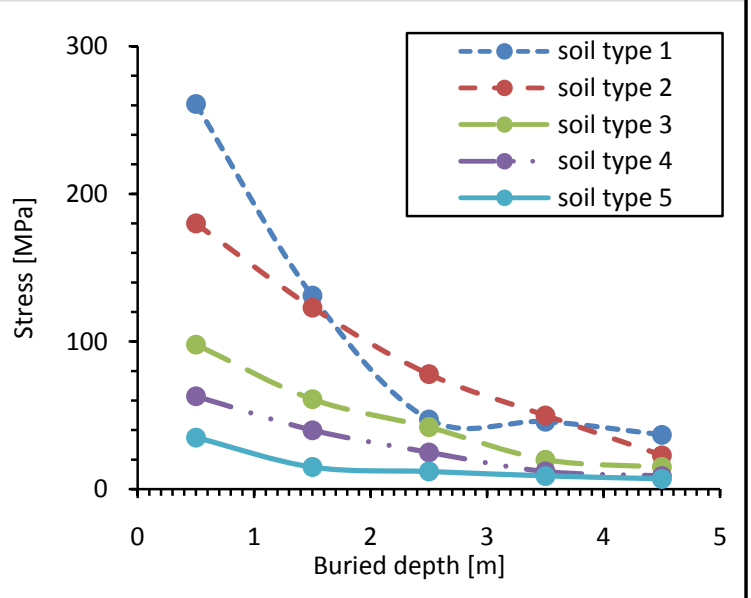

(b)

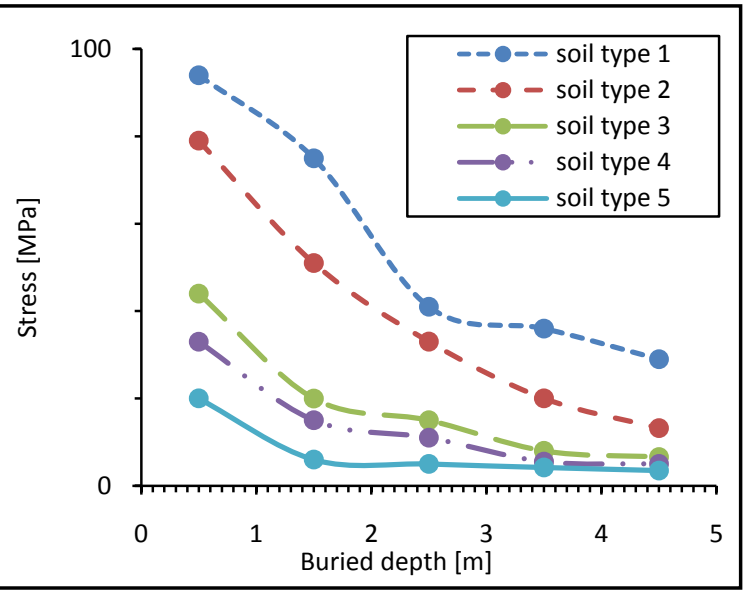

(d)

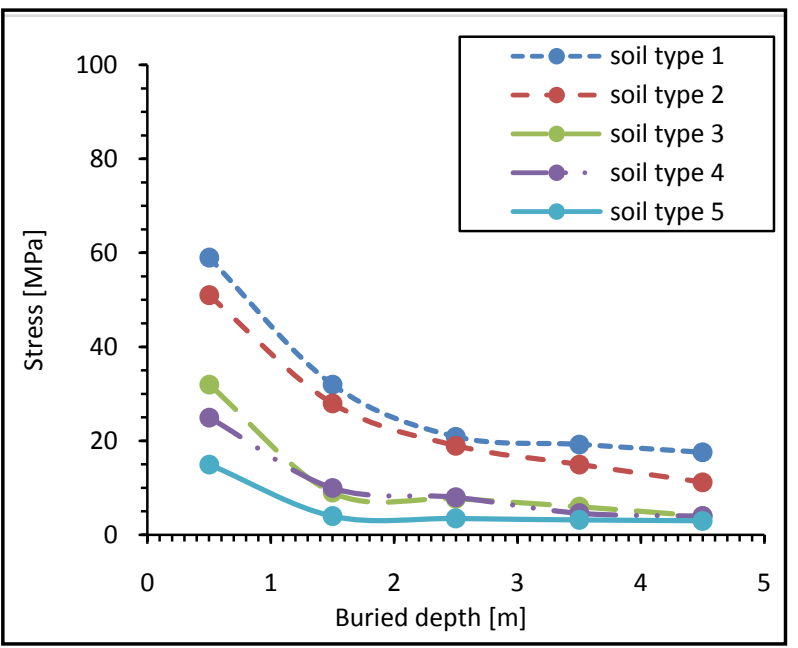

(f)

Figure 10. Maximum principal stresses in the steel pipe with different soil type. (a) $\mathrm{D}=4 \mathrm{in}$; (b) $\mathrm{D}=10 \mathrm{in}$; (c) $\mathrm{D}=20 \mathrm{in}$; (d) $\mathrm{D}=$ 24 in; (e) $\mathrm{D}=30$ in; (f) $\mathrm{D}=44$ in.

\section{Conclusions}

Finite-element analysis of the buried pipeline under vehicle loads was investi- 
gated. Effects of the vehicle parameters, the pipeline parameters and the surrounding soil parameters on the mechanical behavior of the buried steel pipeline were discussed. Based on the study, the following conclusions can be drawn:

(1) Results indicate that maximum principal stresses in a buried pipe under vehicle load are significant for burial depths of lower than $1 \mathrm{~m}$.

(2) For small burial depths, maximum principal stresses in steel pipes are more critical when the vehicle load moves along the pipe axis. However, as burial depth and Young's modulus of the soil increase, the stress values parallel and normal to the pipe axis due to the vehicle motion converge to the same value. Additionally, maximum principal stresses in the steel pipe decrease as the vehicle velocity increases. The magnitude of this decrease is in inversely proportional to the burial depth and Young's modulus of the soil. Moreover, as pipe diameter and burial depth increase, stress diagrams of the steel pipe converge more quickly for different vehicle velocities.

(3) Maximum principal stresses in the pipe decrease as its diameter increase. The magnitude of this decrease is inversely proportional to the burial depth. Additionally, stress diagrams of pipes with different diameters converge more quickly as burial depth and Young's modulus of soil increase. Generally, the decrease in diameter-to-thickness ratio results in lower maximum principal stresses, such that in diameter-to-thickness ratios of smaller than 30 , the maximum principal stress in the steel pipe is negligible.

(4) Maximum principal stress in the steel pipe decreases as Young's modulus of soil decreases, such that for Young's moduli of greater than $20 \mathrm{MPa}$, maximum principal stresses in the steel pipe are negligible. Moreover, maximum principal stresses decrease as Poisson's ratio decreases, the magnitude of which is inversely proportional to the burial depth.

\section{References}

[1] Trott, J.J. and Gaunt, J. (1976) Experimental Pipelines under a Major Road: Performance during and after Road Construction. Transport and Road Research Laboratory, Laboratory Report 692, Crowthorne, Berkshire, UK.

[2] Shuai, J., Wang, X.L. and Ye, Y.X. (2009) Stress Analysis of Pipeline Subject to Surface Load. Journal of China University of Petroleum, 33, 99-103.

[3] Wang, X.L. (2009) Safety Evaluation Method Research on Buried Pipeline in Typical adverse Geological Conditions. China University of Petroleum, Beijing.

[4] Marston, A. and Anderson, A.O. (1913) The Theory of Loads on Pipes in Ditches and Tests of Cement and Clay Drain Tile and Sewer Pipes. Bulletin 3I, Iowa Engineering Station, Iowa State College of Agriculture and Mechanic Arts.

[5] Noor, M.A., and Dhar, A.S. (2003) Three-Dimensional Response of Buried Pipe under Vehicle Loads. Proceedings of the ASCE International Conference on Pipeline Engineering and Construction, Baltimore, 13-16 July 2003, 658-665.

[6] Newmark, N.M. and Hall, W.J. (1979) Pipeline Design to Resist Large Fault Displacement. 1st U.S. National Commission on Excellence in Education (U.S. NCEE)

[7] Wang, L.R.L., O’Rourke, M.J. and Pikul, R.R. (1979) Seismic Response Behavior of Buried Pipelines. Journal of Pressure Vessel Technology, 101, 21-30.

https://doi.org/10.1115/1.3454594 
[8] Selberg, W.L. (1952) Transient Compression Waves from Spherical and Cylindrical Cavities. Arkiv for Fysik, 5, 97-108.

[9] Jordan, D.W. (1962) The Stress Wave from a Finite Cylindrical Explosive Source. Journal of Mathematics and Mechanics, 11, 503-551.

[10] Parnes, R. (1980) Progressing Torsional Loads along a Bore in an Elastic Medium. International Journal of Solids and Structures, 16, 653-670. https://doi.org/10.1016/0020-7683(80)90024-4

[11] Sneddon, I.N. (1952) Stress Produced by a Pulse of Pressure Moving along the Surface of a Semi-Infinite Solid. Rendiconti del Circolo Matematico di Palermo, 2, 57 62. https://doi.org/10.1007/BF02843720

[12] Cheng, F.Y. and Ger, J.F. (1989) Response Analysis of 3-D Pipeline Structures with Consideration of Six component Seismic Input. Proceedings of Symposium on Resent Developments in Lifeline Earthquake Engineering, American Society Mechanical Engineers (ASME) and Japan Society of Mechanical Engineers (JSME), 1, 257271.

[13] Wong, K.C., Datta, S.K. and Shah, A.H. (1986) Three-Dimensional Motion of Buried Pipeline. I: Analysis. Journal of Engineering Mechanics, 112, 1319-1337. https://doi.org/10.1061/(ASCE)0733-9399(1986)112:12(1319)

[14] Liu, M. and Yang, M. (2014) Modeling the Behavior of Natural Gas Pipeline Impacted by Falling Objects. Engineering Failure Analysis, 42, 45-59. https://doi.org/10.1016/j.engfailanal.2014.03.008

[15] Gong, X.N., Sun, Z.J. and Yu, J.L. (2015) Analysis of Displacement of Adjacent Buried Pipeline Caused by Ground Surcharge. Rock and Soil Mechanics, 36, 305-310.

[16] Zhang, J., Liang, Z. and Han, C.J. (2015) Finite Element Analysis of Wrinkling of Buried Pressure Pipeline under Strike-Slip Fault. Mechanika, 21, 180-186. https://doi.org/10.5755/j01.mech.21.3.8891

[17] Zhang, J., Liang, Z. and Zhao, G. (2016) Mechanical Behavior Analysis of a Buried Steel Pipeline Underground Overload. Engineering Failure Analysis, 63, 131-145. https://doi.org/10.1016/j.engfailanal.2016.02.008

\section{Submit or recommend next manuscript to SCIRP and we will provide best service for you:}

Accepting pre-submission inquiries through Email, Facebook, LinkedIn, Twitter, etc. A wide selection of journals (inclusive of 9 subjects, more than 200 journals)

Providing 24-hour high-quality service

User-friendly online submission system

Fair and swift peer-review system

Efficient typesetting and proofreading procedure

Display of the result of downloads and visits, as well as the number of cited articles

Maximum dissemination of your research work

Submit your manuscript at: http://papersubmission.scirp.org/

Orcontactojg@scirp.org 